\title{
Achim Trebst, my senior, and our joint research
}

\author{
Walter Oettmeier
}

(C) Springer Science+Business Media B.V. 2009

\begin{abstract}
In this tribute, I offer my best wishes to Achim Trebst on his 80th birthday on June 9, 2009. At the invitation of Govindjee, I present here a perspective of some of our joint research during 1970s through 2000s.
\end{abstract}

Keyword Herbicides

\section{My perspective on Achim and our joint research}

I wish Achim Trebst a happy 80th birthday. Achim avoided big celebrations for himself, but he offered his coworkers strawberries and cream on his birthdays. Here, I recall our joint collaboration together.

Achim Trebst and I earned our Ph. D. degrees with the same supervisor, Prof. Dr. FriedrichWeygand, at the Organic Chemistry Institute of the Technical University in Munich, Germany. However, Achim had completed his Ph. D. degree, in 1956, more than a decade earlier than I. Unfortunately, Friedrich Weygand died untimely at the age of 58 in 1969. I had to look for a new job. This was provided by Achim Trebst, then already a full professor at the Institute of Plant Biochemistry at the Ruhr-University in Bochum, Germany.

In my work at Bochum, I initially sought out to identify the primary acceptor of Photosystem I (PS I), which at that time was thought to be a flavonoid or a cinnamic acid derivative. This turned out not to be true and later a bound ferredoxin was identified to be the primary electron acceptor of PS I. My joint successful research, with Achim

W. Oettmeier $(\bowtie)$

Lehrstuhl Biochemie der Pflanzen, Ruhr-Universität,

44780 Bochum, Germany

e-mail: walter.oettmeier@rub.de
Trebst, was focussed on doing what we could call "biochemical surgery" of electron transport chain, using new inhibitors, and electron donors and acceptors. Indamine (4,4'-diaminodiphenylamine), N-tetramethylindamine and $\mathrm{N}$-pentamethylindamine were found to be electron donors for the photoreduction of NADP (nicotinamide adenine dinucleotide phosphate) by PS I. NADP reduction is coupled to ATP formation, when indamine and tetramethylindamine are used as electron donors but not when pentamethylindamine is the donor. The lack of ATP formation in the presence of pentamethylindamine is attributed to the fact that upon oxidation of pentamethylindamine a radical is formed but no protons are released in contrast to the two other indamines (Oettmeier et al. 1974; Hauska et al. 1975). A similar situation exists for benzidines as electron donors for Photosystem II (PS II) in Tris-treated chloroplasts. Benzidine upon oxidation releases protons and, consequently, gives rise to ATP-formation, whereas $N$, $N, N^{\prime}, N^{\prime}$-tetramethylbenzidine only yields a radical and does not release protons. Thus, ATP-formation is abolished (Harth et al. 1974).

After a two year stay at the Chemistry Division of Argonne National Laboratory, Ill., USA, with Joseph J. Katz where I mostly worked on the ESR-spectra of chlorophyll liposomes and spin labels, I returned to Bochum in 1976. R. Geiger from the former Hoechst Aktien Gesellschaft in Frankfurt had synthesized a series of polypeptides with sequences from the D2 reaction center protein of PS II. They were coupled to bovine serum albumin and rabbits immunized with them. Thus, we were able to obtain antobodies with high titers in this way (see Geiger et al. 1987).

Together with Udo Johanningmeier, now a Professor of Plant Biochemistry at the University of Halle, Trebst and I studied electron transport and herbicide binding in 
trypsin-treated chloroplasts. The difference between 3(3',4'-dichlorphenyl)-1,1-dimethylurea] (DCMU)-type and phenolic herbicies became evident on trypsin treatment. After trypsin treatment the binding constant of DCMU-type herbicides was drastically increased whereas that of phenolic herbicides remained virtually unchanged (Oettmeier et al. 1982).

In a book chapter "Inhibitor and plastoquinone binding to photosystem II", Trebst and I discussed extensively the differences between "DCMU-type" and phenolic type inhibitors. The binding of photoaffinity labels azido-atrazine, azido-dinoseb and plastoquinone-azide to Photosystem II particles with intact oxygen evolving system or with missing oxygen evolving system was studied. A direct competition between "DCMU-type" inhibitors and plastoquinone at the D1 protein is feasible, though not likely for all the inhibiting compounds of quite different chemistry (Oettmeier and Trebst 1983).

There are a very large number of compounds that inhibit in vitro PS II electron transport. In contrast, electron transport in the reaction centers from photosynthetic bacteria is inhibited only by a very few substances. In collaboration with chemists and biochemists from the Bayer Aktien Gesellschaft, new inhibitors (e.g., thiazoles) were found that inhibited both the photosynthetic bacterial reaction centers as well as PS II (Kluth et al. 1990).

Trebst and I were part of a special program ("Schwerpunkt") of the Deutsche Forschungsgemeinschaft which investigated the food chain, i.e., how from microorganisms through insects and fishes food finally reached humans. In this context, specific and unspecific binding of herbicides was of importance and the binding parameters for both types of binding were evaluated (Oettmeier and Trebst 1987).

In search for new PS II inhibitors, we concentrated mainly on $p$-quinones, heterocyclic $o$-quinones, azaphenanthrenes, acridones and diphenylamines. The binding and displacement behaviour of the new inhibitors was studied using the presence of radioactively labeled herbicides. We also synthesized radioactively labeled photoaffinity labels to identify amino acids in the PS II D1 protein which participate in herbicide binding. In this way, $\mathrm{Tyr}_{237}$ and $\mathrm{Tyr}_{254}$ were found to be responsible for the binding of azido-monuron and $\mathrm{Val}_{249}$ for that of azidoioxynil (Dostatni et al. 1988; Oettmeier et al. 1989).

We extended our studies to find new inhibitors for the mitochondrial NADH-ubiquinone-oxidoreductase (quinolones, acridones), the cytochrome $\mathrm{b} / \mathrm{c}_{1}$-complex (also acridones) and the soluble NADH-ubiquinone-oxidoreductase (acridone-4-carboxylic acids) (Oettmeier et al. 1994). In a Quantitative Structure-Activity Relationship (QSAR), the inhibitory activity of a compound is correlated with physico-chemical parameters like the lipophilicity, the electronegativity or steric factors like the STERIMOL parameters of a substituent. Together with W. Draber and I, Achim Trebst evaluated the QSAR of quinones and acridones in wild type and various mutants of Chlamydomonas reinhardtii. As an example, the QSAR of acridones in the wild type was given. The biological activity of the acridones is described by the following equation:

$\mathrm{pI}_{50}=0.29 \mathrm{~L}_{2}+0.62 \mathrm{~L}_{4}-0.72 \mathrm{~L}_{7}+1.00 \mathrm{~B} 5_{7}$

$\mathrm{n}=11, \mathrm{~F}=9.8, \mathrm{r}=0.94, \mathrm{~s}=0.23$

where, $\mathrm{L}_{2}, \mathrm{~L}_{4}, \mathrm{~L}_{7}$ and $\mathrm{B} 5_{7}$ are the STERIMOL parameters (Verloop 1983), $\mathrm{n}$ is the number of compounds, $\mathrm{F}$ is the (statistical) F-test, $r$ the correlation coefficient and $s$ the standard deviation. The importance of the STERIMOL parameters in the regression equation suggests that the orientation of the acridones in the $\mathrm{Q}_{\mathrm{B}}$ binding niche is mainly by hydrophobic interaction that is very sensitive to steric restrictions of certain amino acid side chains (Draber et al. 1995).

Achim Trebst retired in 1994 but still kept a functioning laboratory with Brigitte Depka as his technician. He became interested in herbicides like isoxaflutole or pyrazolates which affect the hydroxyphenylpyruvate dioxygenase. It turned out that decyl-plastoquinone reversed the herbicide-induced inhibition and inactivation of PS II in a very short time. In high light longer than $1 \mathrm{~h}$, decyl-plastoquinone loses effectiveness, but a synthetic short chain and membrane permeable derivative of tocopherol retards the inhibitory effects on PS II and the degradation of the PS II D1 protein (Trebst et al. 2004).

Singlet oxygen, formed in the PS II reaction center, was shown to trigger the degradation of the PS II D1 protein. Tocopherol biosynthesis in the alga Chlamydomonas reinhardtii was inhibited under conditions in which plastoquinone did not limit the photosynthesis rate. In the presence of isoxaflutole and in high light for $2 \mathrm{~h}$, photosynthesis in vivo and PS II were inactivated, the D1 protein was degraded and the tocopherol pool was depleted. The inhibited system could be fully restored upon the addition of a chemical singlet oxygen quencher like diphenylamine or by synthetic cell wall permeable short chain $\alpha$ - and $\gamma$-tocopherol derivatives (Kruk et al. 2005).

Achim Trebst is a very patient person. I remember the IInd International Congress on Photosynthesis in Stresa, Italy in 1971. On the first day of the Congress, Trebst gave the opening lecture. His slides were in perfect order, but the projectionist, obviously inexperienced, managed to put the slides into the projector in the wrong way. It took then several attempts to arrange them in the correct orientation (note: there are eight psossibilities to insert a slide in the slot of a projector). Though the situation was very frustrating, Achim did not loose his temper. Then, Giorgio 


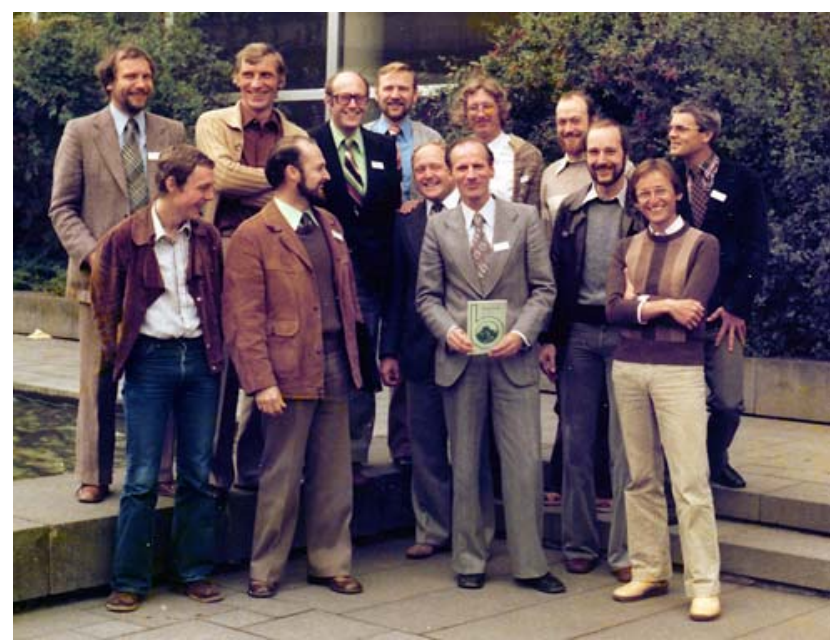

Fig. 1 Achim Trebst holding the program for Botanikertagung in Marburg, Germany, with others. Back row (left to right): Ahlert Schmidt, Jens-Dirk Schwenn, Walter Oettmeier (the author), Günther Wildner, unidentified, unidentified, and Peter Böger. Front row (left to right):.unidentified, Richard Berzborn, Erich Elstner, Achim Trebst, Wolfgang Haehnel, and Herbert Böhme

Forti, the President of the Congress, thought that Trebst has used up his allotted time and entered the stage ringing a huge brass bell. This was repeated every two minutes. Achim was not disturbed at all and finished his lecture as planned.

During his time as a full Professor of Plant Biochemistry, Achim Trebst and his collaborators gathered every workday morning at 11.00 am for a cup of coffee. Then science, research results, things of mutual interest, student courses and examinations were discussed. It should be noted that no student of Achim ever failed a diploma or Ph. D. examination.

During his scientific career, Achim Trebst has received three honorary Ph.D. degrees: from Purdue University, West Lafayette, Indiana, USA; Stockholm University in Sweden and University of Düsseldorf, Germany.

I end this Tribute by showing a photograph of Achim Trebst (with others in Marburg; see Fig. 1) and by offering him my continued friendship.

Acknowledgment I thank Govindjee for inviting me to write this perspective for 'Photosynthesis Research' on my joint collaboration with Achim Trebst. I also thank him for editing this manuscript.

\section{References}

Dostatni R, Meyer HE, Oettmeier W (1988) Mapping of two tyrosine residues involved in the quinone $\left(\mathrm{Q}_{\mathrm{B}}\right)$ binding site of the $\mathrm{D}-1$ reaction center polypeptide of photosystem II. FEBS Lett 239:207-221
Draber W, Trebst A, Oettmeier W (1995) Structure-activity relationships of quinone and acridone photosystem II inhibitors. In: Hansch C, Fujjita T (eds) Classical and three-dimensional QSAR in Agrochemistry American Chemical Society Symposium Series 606. Washington DC, pp 186-198

Geiger R, Berzborn RJ, Depka B, Oettmeier W, Trebst A (1987) Sitedirected antisera to the D-2 polypeptide subunit of photosystem II. Z Naturforsch 42c:491-498

Harth E, Oettmeier W, Trebst A (1974) Native and artificial energy conserving sites operating in coupled electron donor systems for photosystem II. FEBS Lett 43:231-234

Hauska G, Oettmeier W, Reimer S, Trebst A (1975) Shuttles of artificial electron donors for photosystem I across the thylakoid membrane. Z Naturforsch 30c:37-45

Kluth JF, Tietjen KG, Andree R, Ewald G, Oettmeier W, Trebst A (1990) Thiazoles that inhibit photosynthetic reaction centers both in purple bacteria and chloroplasts. Pestic Sci 30:424-427

Kruk J, Holländer-Czytko H, Oettmeier W, Trebst A (2005) Tocopherol as singlet oxygen scavenger in photosystem II. J Plant Physiol 162:749-757

Oettmeier W, Trebst A (1983) Inhibitor and plastoquinone binding to photosystem II. In: Inoue Y, Crofts AR, Govindjee, Murata N, Renger G, Satoh K (eds) The oxygen evolving system of photosynthesis. Academic Press, Tokyo, pp 411-420

Oettmeier W, Trebst A (1987) Zum Wirkungsmechanismus von Photosynthese-Hemmstoffen und -Herbiziden. In: Bioakkumulation in Nahrungsketten. Herausgeber Lillelund K., de Haar U., Elster H. J., Karbe L., Schwoerbel I. und Simonis W (eds) Verlag Chemie, Weinheim, pp 254-257

Oettmeier W, Reimer S, Trebst A (1974) Substituted indamines as electron donors in photoreductions by photosystem I. Plant Sci Lett 2:267-271

Oettmeier W, Johanningmeier U, Trebst A (1982) Inhibitors of plastoquinone function as a tool for identification of its binding proteins in chloroplasts. In: Trumpower BL (ed) Function of quinones in energy conserving systems. Academic Press, New York, pp 425-441

Oettmeier W, Masson K, Höhfeld J, Meyer HE, Pfister K, Fischer HP (1989) $\left[{ }^{125} \mathrm{I}\right]$ Azido-ioxynil labels $\mathrm{Val}_{249}$ of the photosystem II D-1 reaction center protein, Z. Naturforsch 44c:444-449

Oettmeier W, Masson K, Soll M, Reil E (1994) Acridones and quinolones as inhibitors of ubiquinone functions in the mitochondrial respiratory chain. Biochem Soc Trans 22:213-216

Trebst A, Depka B, Jäger J, Oettmeier W (2004) Reversal of the inhibition of photosynthesis by herbicides affecting hydroxyphenylpyruvate dioxygenase by plastoquinone and tocopherol derivatives in Chlamydomonas reinhardtii. Pest Manag Sci 60:669-674

Verloop A (1983) The sterimol approach: further development of the method and new applications. In: Miyamoto J, Kearny PC (eds) Pesticide chemistry, human welfare and the environment, vol 1. Pergamon Press, Oxford, pp 563-566 